\title{
Effect of apomorphine on cognitive performance and sensorimotor gating in humans
}

\author{
Arnt F. A. Schellekens • K. P. Grootens • C. Neef • \\ Kris L. L. Movig • J. K. Buitelaar • B. Ellenbroek • \\ R. J. Verkes
}

Received: 19 February 2009 / Accepted: 23 September 2009 /Published online: 16 October 2009

(C) The Author(s) 2009. This article is published with open access at Springerlink.com

\begin{abstract}
Introduction Dysfunction of brain dopamine systems is involved in various neuropsychiatric disorders. Challenge studies with dopamine receptor agonists have been performed to assess dopamine receptor functioning, classically using the release of growth hormone (GH) from the hindbrain as primary outcome measure. The objective of
\end{abstract}

Electronic supplementary material The online version of this article (doi:10.1007/s00213-009-1686-1) contains supplementary material, which is available to authorized users.

A. F. A. Schellekens $(\bowtie) \cdot$ K. P. Grootens $\cdot$ J. K. Buitelaar R. J. Verkes

Department of Psychiatry, Radboud Medical Centre Nijmegen, Reinier Postlaan 10, 966 P.O. Box 9101, 6500 HB Nijmegen,

The Netherlands

e-mail: a.f.a.schellekens@psy.umcn.nl

A. F. A. Schellekens • K. P. Grootens • J. K. Buitelaar •

R. J. Verkes

Department of Psychiatry, University Medical Centre,

Nijmegen, The Netherlands

A. F. A. Schellekens • K. P. Grootens • J. K. Buitelaar •

R. J. Verkes

Donders Centre for Brain and Cognition,

Nijmegen, The Netherlands

C. Neef

Department of Pharmacy and Toxicology,

Maastricht University Medical Centre,

Maastricht, The Netherlands

K. L. L. Movig

Department of Clinical Pharmacy, Medisch Spectrum Twente,

Enschede, The Netherlands

B. Ellenbroek

Evotec AG,

Hamburg, Germany the current study was to assess dopamine receptor functioning at the forebrain level.

Methods Fifteen healthy male volunteers received apomorphine sublingually $(2 \mathrm{mg})$, subcutaneously $(0.005 \mathrm{mg} / \mathrm{kg})$, and placebo in a balanced, double-blind, cross-over design. Outcome measures were plasma GH levels, performance on an $\mathrm{AX}$ continuous performance test, and prepulse inhibition of the acoustic startle. The relation between central outcome measures and apomorphine levels observed in plasma and calculated in the brain was modeled using a two-compartmental pharmacokinetic-pharmacodynamic analysis.

Results After administration of apomorphine, plasma GH increased and performance on the $\mathrm{AX}$ continuous performance test deteriorated, particularly in participants with low baseline performance. Apomorphine disrupted prepulse inhibition (PPI) on high-intensity $(85 \mathrm{~dB})$ prepulse trials and improved PPI on low intensity $(75 \mathrm{~dB})$ prepulse trials, particularly in participants with low baseline PPI. High cognitive performance at baseline was associated with reduced baseline sensorimotor gating. Neurophysiological measures correlated best with calculated brain apomorphine levels after subcutaneous administration.

Conclusion The apomorphine challenge test appears a useful tool to assess dopamine receptor functioning at the forebrain level. Modulation of the effect of apomorphine by baseline performance levels may be explained by an inverted U-shape relation between prefrontal dopamine functioning and cognitive performance, and mesolimbic dopamine functioning and sensorimotor gating. Future apomorphine challenge tests preferentially use multiple outcome measures, after subcutaneous administration of apomorphine.

Keywords Dopamine · Apomorphine - Cognition · Prepulse inhibition $\cdot$ Neuroendocrine 


\section{Introduction}

Dysfunctioning of dopaminergic neurocircuitry has been implicated in various neuropsychiatric disorders including substance dependence, Tourette's syndrome, schizophrenia, and others (see (Kienast and Heinz 2006) for a comprehensive review). Pharmacological challenge tests using dopamine receptor agonists provide a useful tool for investigating sensitivity of brain dopamine receptors. Classically, the release of growth hormone (GH) after administration of a dopamine agonist, e.g., apomorphine (APO) or bromocriptine has been used to assess central dopamine sensitivity, showing reduced plasma GH levels in patients suffering from alcohol dependence, major depression, and schizophrenia (Duval et al. 2000; Mokrani et al. 1995; Schmidt et al. 2001).

The GH response to APO is mediated by dopamine receptors in the hindbrain (pituitary) region, whereas prefrontal and mesolimbic dopamine neurotransmission are more relevant for human behavior and neuropsychiatric disorders (Meister et al. 1985; Seema0n and Van Tol 1993). This report describes a dopamine challenge in healthy human volunteers, using three indices of dopamine function: plasma GH levels, performance on a continuous performance test, and prepulse inhibition of the acoustic startle response.

Dopamine is involved in cognitive functioning, including perceptual speed (spatial), working memory, and response inhibition (Backman et al. 2000; Cropley et al. 2006; Reeves et al. 2005). Deficits in cognitive performance on various cognitive tasks have been described in disorders with a decrease in prefrontal dopamine functioning such as attention-deficit hyperactivity disorder (ADHD) and schizophrenia (Iversen and Iversen 2007). Evidence from both animal and human studies, using pharmacological stimulation of dopamine receptors, suggests that both too little and too much stimulation of dopamine impairs cognitive performance (Cools 2008; Gibbs and D'Esposito 2005; Vijayraghavan et al. 2007).

Individuals with poor baseline performance on an n-back task, with presumed suboptimal prefrontal dopamine functioning, improved after administration of the dopamine agonist D-amphetamine, whereas individuals with high baseline performance deteriorated (Mattay et al. 2000; Mattay et al. 2003). Using the dopamine agonist bromocriptine, similar findings have been found on a variety of cognitive tasks including the Wisonsin Card Sorting Task (set shifting task), the Stroop task (interference task), and Corsi Block Tapping Task (spatial span task) (Kimberg et al. 1997b; Mehta et al. 2001).

In addition, amphetamine improved performance on a continuous performance task in individuals scoring low on novelty seeking with presumed low levels of dopamine and impaired performance in individuals scoring high on novelty seeking with presumed high dopamine levels (Fleming et al. 1995). Thus, a specific level of dopamine appears necessary for optimal functioning of the prefrontal cortex following an inverted U-dose-response curve (Gibbs and D'Esposito 2005; Swainson et al. 2000; Vijayraghavan et al. 2007; Zahrt et al. 1997).

Administration of the dopamine agonist APO has been shown to disrupt performance on a working memory task in healthy human volunteers, probably by altered brain activity in the dorsolateral prefrontal cortex (Fletcher et al. 1996; Friston et al. 1992; Grasby et al. 1993). We selected the AX continuous performance test (AX-CPT) because previous pharmacological studies with dopaminergic medication (apomorphine and cabergoline) have shown clear effects on task performance using this task (Frank and O'Reilly 2006; Schellekens et al. 2009). We hypothesized that administration of APO to healthy controls would change task performance, depending on baseline task performance, such that performance improves in those subjects with low baseline performance and deteriorates in those with high baseline performance.

Prepulse inhibition (PPI), the phenomenon that a startle response elicited by a sudden intense stimulus (noise burst) is inhibited, when it is preceded by a weaker stimulus, has also been shown to be related to dopamine functioning. Reductions of PPI have been shown in disorders in which an increase in dopamine functioning has been hypothesized, such as schizophrenia, obsessive compulsive disorder, and tic disorder (see Braff et al. 2001 for a review on PPI paradigms in humans). Moreover, dopamine agonists have been shown to reduce PPI in animals and humans (see for further reviews: Braff et al. 2001, Swerdlow et al. 2000; Swerdlow et al. 2001a, b). An inverted-U association between PPI levels and dopamine functioning has been hypothesized, since the disruptive effects of the dopamine agonist pergolide and amantadine on PPI in humans have been shown only in subjects with high baseline PPI levels, suggesting excessive dopaminergic stimulation in subjects with high levels of baseline PPI (Bitsios et al. 2005; Talledo et al. 2009b).

Although the neuronal circuitry underlying PPI is extensive, there is a large amount of evidence indicating that the APO-induced deficit in PPI depends predominantly on stimulation of mesolimbic dopamine receptors in the nucleus accumbens (Swerdlow et al. 2000; Swerdlow et al. 2001a, b). We expected administration of APO to change PPI, depending on baseline levels of PPI, such that PPI increases in those subjects with low baseline PPI and reduces in those with high baseline PPI.

The relationship between APO levels in blood, brain, and GH release was first explored by Aymard et al. (2003). They showed that APO levels in the second compartment 
(i.e., the concentration of APO in cerebrospinal fluid; CSF), correlated better with plasma GH levels than APO levels in the first compartment (i.e., the concentration of APO in plasma) (Aymard et al. 2003; Hofstee et al. 1994). As shown by Hofstee et al. (1994), APO levels in CSF can be reliably calculated from plasma APO concentrations using pharmacokinetic modeling (Hofstee et al. 1994). We measured plasma APO levels and calculated APO levels in the CSF and hypothesized that central effects of APO can best be modeled using calculated APO levels in the CSF compared to observed APO levels in the plasma. We used both subcutaneous (s.c.) and sublingual (s.l.) administration of APO in order to be able to model the central effect of APO in different kinetic profiles and to assess which mode of administration was most appropriate for use in a challenge test.

\section{Methods and materials}

\section{Design}

A double-blind, placebo-controlled challenge study was performed in 15 healthy males using a balanced, crossover design with three treatment conditions in a doubledummy approach: APO $2 \mathrm{mg}$ s.1./placebo s.c., APO $0.005 \mathrm{mg} / \mathrm{kg}$ s.c./placebo s.l., and placebo s.1./s.c.. Low doses of APO were used because of poor tolerability at higher doses (nausea, vomiting, and collapse, unpublished pilot studies). The study protocol was approved by the regional ethical board.

\section{Participants}

Participants were recruited through advertisements in regional newspapers and at the campus of Radboud University Nijmegen. After written informed consent, participants were screened for any medical condition, including laboratory abnormalities and the use of medication or drugs within 2 months prior to the study. Auditory acuity was evaluated during medical examination by use of tuning fork tests (Weber, Rinne, and Swabach) and whisper tests.

Psychiatric history was assessed using the Dutch version of the Mini International Neuropsychiatric Interview for psychiatric disorders version 2.1 and the Dutch version of the ADHD rating scale (Sandra Kooij et al. 2008; Sheehan et al. 1998; van Vliet and de Beurs 2007). To assess history of drug and alcohol use, we used the Dutch version of the Addiction Severity Index, Section 4 (Langeland et al. 2001; McLellan et al. 1992). Participants with any psychiatric (family) history including substance use disorders and habitual smoking (daily nicotine use) were excluded. Out of 16 screened individuals, 15 were eligible, mean age (SD) 25.2 (5.9) years. Participants were not allowed to smoke or use caffeine during study mornings, or take alcohol 2 days before study days.

\section{Measurements}

\section{Plasma apomorphine and growth hormone levels}

To assess plasma APO and GH levels, blood $(4 \mathrm{ml})$ was taken. After centrifugation, 2.0-ml samples were kept on ice and stored at $-30^{\circ} \mathrm{C}$. APO levels were assessed by highpressure liquid chromatography with electrochemical detection (Essink et al. 1991). GH levels were assessed by radio immuno assay, using antiserum raised in guinea pig. The first $(80 / 505)$ international standard for GH was used for the standard curve with a detection limit of $1.6 \mathrm{mIU} / \mathrm{L}$.

Two participants with baseline GH levels $>10 \mathrm{U} / 1$ were excluded from analysis. Plasma APO levels were available for nine of 15 individuals due to contamination of the antioxidant in one series of batches.

\section{AX continuous performance task}

In the AX continuous performance task (AX-CPT), single white letters were consecutively shown on a black screen (interstimulus interval $=1,300 \mathrm{~ms}$ ). Participants were instructed to give a target response (right button press) after the probe "X", if preceded by a cue "A", or a nontarget response (left button press) after any other combination of letters (van der Linden et al. 2006). To increase task difficulty, two distracter letters were presented between cue and probe (van der Linden et al. 2006). To increase sensitivity for impulsive response styles (commission errors), $70 \%$ were target trials (Braver et al. 2001). Responses were scored in a window between 100 and 2,000 ms after stimulus onset. Performance during each session was calculated as the mean reaction time and accuracy on AX trials (the percentage commission errors). Non responses (omissions) were not taken into account given the low number $(<1 \%)$. A median split on baseline accuracy was used to divide high and low baseline performers (Kimberg et al. 1997a).

\section{Prepulse inhibition}

Reflex eyeblink responses were measured as electromyographic activity over the right orbicularis oculi muscle with a sampling frequency of $1,000 \mathrm{~Hz}$ (van der Linden et al. 2006). Background sound consisted of $70 \mathrm{~dB}$ white noise pulse-alone trials of $105 \mathrm{~dB}$ and white noise bursts with instant rise time. Prepulse trials consisted of either 75 or $85 \mathrm{~dB}$ white noise bursts preceding $105 \mathrm{~dB}$ pulses. Pulse 
duration was $20 \mathrm{~ms}$ for prepulses and $40 \mathrm{~ms}$ for startle pulses. Interstimulus interval was $100 \mathrm{~ms}$, intertrial intervals ranged between 8-12 s randomly. Each PPI measurement started with 15 habituation trials (105 dB PA trials) that were subsequently excluded from the analysis followed by 12 trials of each type $(105 \mathrm{~dB}, 85 / 105 \mathrm{~dB}, 75 / 105 \mathrm{~dB})$ in a pseudo-random order.

Data cleaning was performed off-line with MIDAC software (test organizer-MIDAC polygraphy module, Instrumentation Service, UMC St Radboud, Nijmegen, The Netherlands), with a response window from 20-150 ms after stimulus onset. Startle responses with an inconstant baseline $20 \mathrm{~ms}$ before the stimulus with a response to the prepulse or trials in which no startle response was detected were excluded from further calculations.

The average amplitude of startle responses was calculated for each trial type $(105 \mathrm{~dB}, 75 / 105 \mathrm{~dB}$ and $85 / 105 \mathrm{~dB})$ per startle session (i.e., six sessions per treatment condition). Percentage PPI was calculated for $75 / 105 \mathrm{~dB}$ and $85 / 105 \mathrm{~dB}$ trials, per startle session, as follows: $\left[\left(M_{\text {amplitude } \mathrm{PA}}-\right.\right.$ $\left.\left.M_{\text {amplitude PP }}\right) /\left(M_{\text {amplitude PA }}\right)\right] * 100 \%$. A median split on baseline PPI (both $75 / 105 \mathrm{~dB}$ and $85 / 105 \mathrm{~dB}$ ) was used to divide high and low baseline sensorimotor gaters (Bitsios et al. 2005; Talledo et al. 2009a).

\section{Procedure}

Study mornings started at 8:30 a.m. with a standardized light breakfast. Measurements were performed, once before and five times after drug administration, starting with blood sampling, followed by a 9-min startle session and, consecutively, 10-min AX-CPT, each cycle lasting $20 \mathrm{~min}$ (Fig. 1). Treatment conditions were 10 to 25 days apart.

Data analysis

Statistical Package for the Social Sciences (version 16.0) under Windows was used for statistical analysis, with $\alpha$ set at.05 (two-sided). The effect of APO on GH, performance on the CPT-AX, and acoustic startle was analyzed using GLM repeated measures analysis of variance, with treatment (APO s.l., APO s.c., and placebo) and time (baseline, T1, T2, T3, T4, and T5) as withinsubject factors. Scores on each outcome measure at baseline were used to divide subjects by median split into low and high performers so that we could examine the effect of APO on these two groups for each outcome measure a with group as a between-subject factor. In order to control for a learning effect over the different sessions, order was entered as a between-subjects factor in the analysis of the AX-CPT. Since both the factors, time and treatment, have two or more degrees of freedom, Greenhouse-Geisser correction was used, epsilon values and adjusted $p$ values are reported.

In order to identify the specific time points with the largest effect of APO, simple contrasts to baseline were analyzed post hoc, only when the omnibus test showed a significant interaction effect. To assess the relation between baseline task performance on the AX-CPT and baseline PPI, we computed Pearson's correlation between speed and accuracy on the AX-CPT and PPI on 75/105 and $85 / 105 \mathrm{~dB}$.

Individual curves of APO levels in the first and second compartment were fitted in a previously validated algorithm in MW/Pharm, a software package developed to study the clinical effect of APO, e.g., in patients suffering from Parkinson's disease (Mediware, version 3.60; Hofstee et al. 1994; Neef et al. 1994; Neef and van Laar 1999). Individual fits were based on plasma APO levels, individual pharmacokinetic parameters (volume of distribution, rate constants for elimination and intercompartmental exchange, renal function, and body mass index), and population kinetics. We computed Pearson's correlations between the central outcome measures and time-locked APO levels both in the first and second compartment (plasma and CSF).

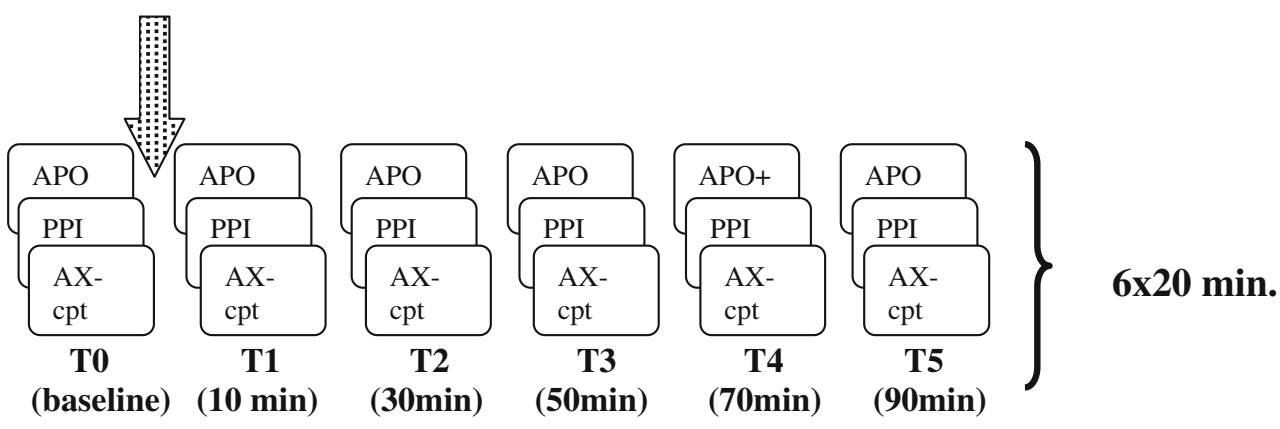




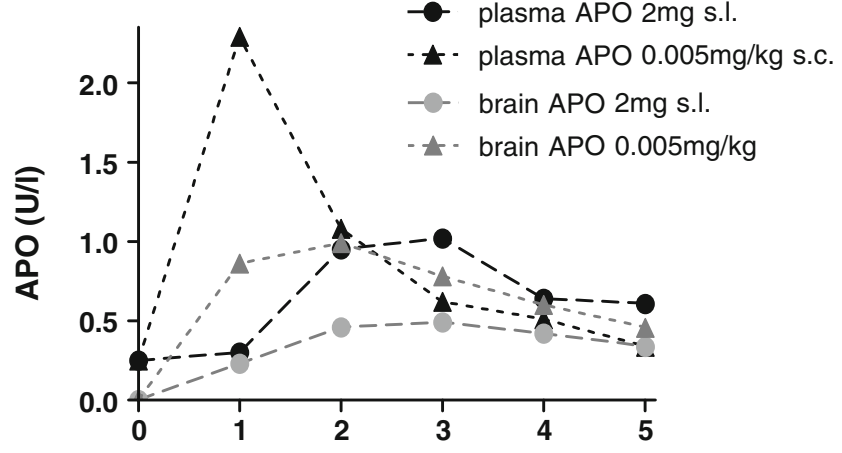

Fig. 2 Results: plasma apomorphine (APO) concentration and APO levels as estimated in the second compartment after oral $(2 \mathrm{mg})$ and sublingual $(0.005 \mathrm{mg} / \mathrm{kg})$ administration

\section{Results}

Plasma apomorphine and growth hormone levels

Both s.c.- and s.l.-administered APO resulted in detectable plasma APO levels (Fig. 2). GH levels increased after administration of APO, see Table 1 and Fig. $3(\mathrm{~F}(10,12)=$
8.4, $p<.001)$. Post hoc analysis showed that the effect of APO was mainly at $50 \mathrm{~min}$ after s.c. administration $(\mathrm{F}(1,12)=18.3$, $p=.001)$.

AX continuous performance task

Baseline task performance did not differ between treatments (commission errors: $\mathrm{F}(2,14)=0.6, p=.547$; reaction time: $\mathrm{F}$ $(2,14)<.01, p=.977)$. There was no effect of order on task performance $(\mathrm{F}(3.3,14)=.6, p=.611)$. There was no difference in age or APO levels between the median split groups (see Supplementary Table 1a). The percentage commission errors increased after APO, particularly in subjects with more error responses at baseline, see Table 1 and Fig. $4 \mathrm{a}(\mathrm{F}(3.2,14)=3.5, p=.030)$. Mean reaction time on AX-trials increased after APO in subjects with slow baseline responses, see Table 1 and Fig. $4 \mathrm{~b}(\mathrm{~F}(4.2,14)=$ 2.9, $p=.030)$.

Post hoc analysis showed that the effect of APO on both error percentage and reaction time was mainly at $40 \mathrm{~min}$ after s.c. administration (error percentage: $F(1,14)=38.1$, $p<.001$, reaction time: $\mathrm{F}(1,14)=21.6, p=.001)$.
Table 1 Results: baseline values and effect of treatment with apomorphine (APO) on plasma growth hormone $(\mathrm{GH})$ levels, performance on the AXcontinuous performance task (AX-CPT), and prepulse inhibition (PPI)
Time main effect of time, treatment main effect of treatment, Time*treatment time by treatment interaction effect, Time*treatment* baseline time by treatment by baseline performance interaction effect

\begin{tabular}{|c|c|c|c|c|}
\hline Outcome measure & Mean at baseline (SD) & F-Statistic (df) & $\varepsilon$-value & $p$ value \\
\hline GH & $N A$ & & & \\
\hline -Time & & $13.4(1.8,12)$ & .36 & $<.001$ \\
\hline -Treatment & & $10.9(1.7,12)$ & .87 & .001 \\
\hline -Time*treatment & & $8.4(2.7,12)$ & .27 & $<.001$ \\
\hline CPT-AX, reaction time (msec) & $347.91 \mathrm{~ms}(66.61)$ & & & \\
\hline -Time & & $2.1(3.3,14)$ & .67 & .107 \\
\hline -Treatment & & $2.7(1.9,14)$ & .96 & .090 \\
\hline -Time*treatment & & $1.7(4.2,14)$ & .42 & .157 \\
\hline -Time*treatment*baseline & & $2.9(4.2,14)$ & & .030 \\
\hline CPT-AX, commission errors $(\%)$ & $4.8 \%(5.4)$ & & & \\
\hline -Time & & $1.0(3.3,14)$ & .67 & .399 \\
\hline -Treatment & & $0.4(1.4,14)$ & .71 & .580 \\
\hline -Time*treatment & & $0.5(3.2,14)$ & .32 & .675 \\
\hline -Time*treatment*baseline & & $3.5(3.2,14)$ & & .030 \\
\hline PPI 75/105 dB (\%) & $9.7 \%(22.6)$ & & & \\
\hline -Time & & $1.1(3.7,14)$ & .73 & .381 \\
\hline -Treatment & & $2.2(1.6,14)$ & .78 & .143 \\
\hline -Time*treatment & & $1.7(5.0,14)$ & .50 & .161 \\
\hline -Time*treatment*baseline & & $2.8(5.0,14)$ & & .024 \\
\hline PPI 85/105 dB (\%) & $22.2 \%(24.6)$ & & & \\
\hline -Time & & $2.5(3.5,14)$ & .70 & .040 \\
\hline -Treatment & & $3.5(1.5,14)$ & .75 & .050 \\
\hline -Time*treatment & & $1.5(4.9,14)$ & .49 & .154 \\
\hline -Time*treatment*baseline & & $1.4(4.9,14)$ & & .182 \\
\hline
\end{tabular}




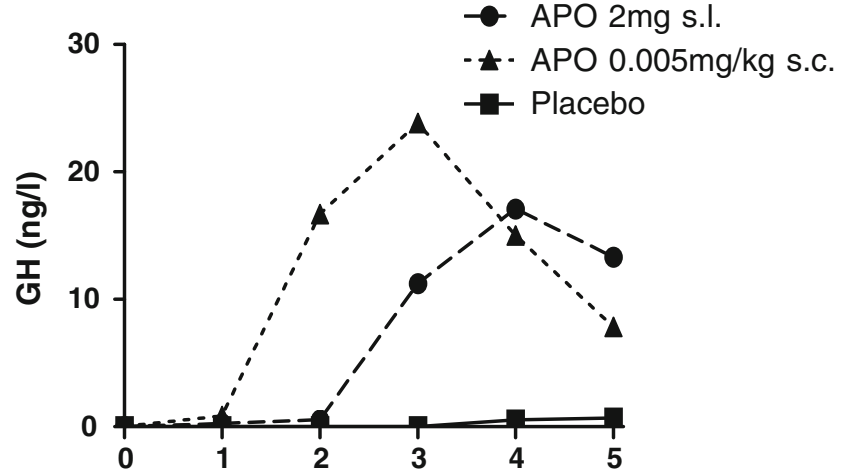

Fig. 3 Results: plasma growth hormone levels before and after sublingual $(2 \mathrm{mg})$ and subcutaneous $(0.005 \mathrm{mg} / \mathrm{kg})$ administration of apomorphine (APO)

Prepulse inhibition

The number of excluded trials increased between baseline and $\mathrm{T} 5$; from $13 \%$ to $26 \%$ for $75 / 105 \mathrm{~dB}(\mathrm{~F}(5,14)=4.7$, $p=.001$ ), from $35 \%$ to $48 \% 105 \mathrm{~dB} \quad(\mathrm{~F}(5,14)=4.8$, $p=.001)$, and from $24 \%$ to $32 \% 85 / 105 \mathrm{~dB}(\mathrm{~F}(5,14)=$ $3.0, p=.018)$. This is mainly caused by an increase in the number of non responses. The number of excluded trials did not differ over the three drug conditions $(105 \mathrm{~dB}$ trials:
$\mathrm{F}(10,14)=1.1, p=.331,75 / 105 \mathrm{~dB}$ trials: $\mathrm{F}(10,14)=0.5$, $p=.853,85 / 105 \mathrm{~dB}$ trials: $\mathrm{F}(10,14)=0.5, p=.900)$ indicating no difference in habituation to the startle stimulus over all treatment conditions. For the results of the analysis on startle amplitudes (see Supplementary Table 2 and Supplementary Figs. 1a-c).

Baseline PPI did not differ between treatments (PPI 75/ 105 dB: $\mathrm{F}(2,14)=0.4, p=.686$, PPI $85 / 105 \mathrm{~dB}: \mathrm{F}(2,14)<$ $0.1, p=.911$ ). There was no difference in age or APO levels between the median split groups (see Supplementary Table 1b). PPI decreased after administration of APO for high-intensity prepulse trials $(85 / 105 \mathrm{~dB})$, see Table 1 and Fig. 5a $(\mathrm{F}(1.5,14)=3.5, p=.050)$. Baseline PPI did not modulate the effect of APO on PPI in high-intensity prepulse trials $(\mathrm{F}(4.9,14)=1.4, p=.182)$. PPI increased after administration of APO for low intensity prepulse trials $(75 / 105 \mathrm{~dB})$ in subjects with low baseline PPI, see Table 1 and Fig. $5 \mathrm{~b}(\mathrm{~F}(5.0,14)=2.8, p=.024)$.

Post hoc analysis showed that the effect of APO on PPI was mainly at $30 \mathrm{~min}$ after s.c. administration $(85 / 105 \mathrm{~dB}$ : $\mathrm{F}(1,14)=6.0, p=.030 ; 75 / 105 \mathrm{~dB}: \mathrm{F}(1,14)=10.1$, $p=.008)$.

Baseline PPI levels for low intensity prepulse trials were inversely correlated with baseline accuracy on task performance $(75 / 105 \mathrm{~dB}: \mathrm{R}=-.59, p=.021)$.

a) Percentage commission errors on CPT-AX, by baseline task performance.

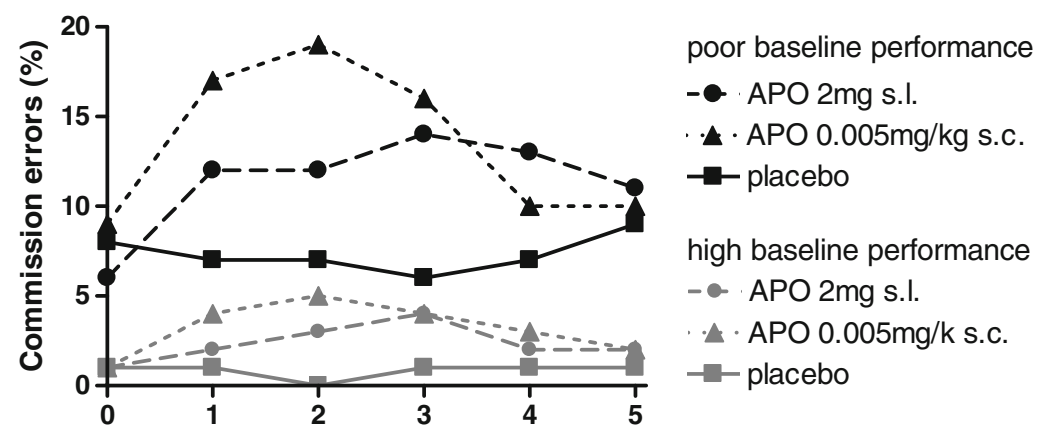

b) Reaction time on CPT-AX, by baseline task performance.

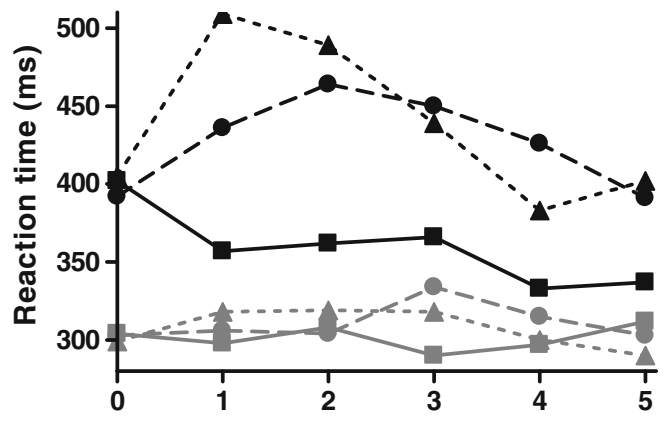

poor baseline performance

- $2 \mathrm{mg} \mathrm{s.l}$.

. $0.005 \mathrm{mg} / \mathrm{kg} \mathrm{s.c.}$

$\rightarrow$ placebo

high baseline performance

- $2 \mathrm{mg} \mathrm{s.l.}$

$0.005 \mathrm{mg} / \mathrm{kg}$ s.c.

- placebo

Fig. 4 Results: performance on AX-continuous performance task (CPT-AX) before and after sublingual $(2 \mathrm{mg}$ ) and subcutaneous $(0.005 \mathrm{mg} / \mathrm{kg})$ administration of apomorphine (APO). a Percentage commission errors on CPT-AX by baseline task performance. b Reaction time on CPT-AX by baseline task performance 
Pharmacokinetic/Pharmacodynamic analysis

The effect of APO on the outcome measures showed close resemblance with the kinetics of APO (Fig. 2, 3, 4, 5). The relation between APO levels and the observed effects could best be modeled using S-curves (Fig. 6). Central measures correlated best with APO levels in the second compartment after s.c. administration, GH levels, and accuracy on the AX-CPT in particular (Table 2).

\section{Adverse events}

Nausea was reported by five participants, between 10 and $40 \mathrm{~min}$, only after s.c. administration of APO. Yawning and weariness were reported in all conditions (placebo: seven participants, APO s.l. ten participants, and APO s.c. 12 participants).

\section{Discussion}

Administration of the direct dopamine receptor agonist APO to healthy individuals resulted in increased plasma GH levels and disrupted performance on the AX-CPT as predicted. APO improved PPI in prepulse trials of low intensity $(75 / 105 \mathrm{~dB})$ in subjects with poor baseline sensorimotor gating and disrupted PPI in high-intensity prepulse trials $(85 / 105 \mathrm{~dB})$.
Elevated levels of plasma GH after administration of APO are in line with previous studies that have shown GH responses after comparable doses of APO in healthy controls and patients suffering from schizophrenia, major depression, and alcohol dependence (Schmidt et al. 2001). The dose of APO currently administered appears to be sufficient to stimulate central dopamine receptors.

The observed deterioration in cognitive performance after APO is in line with other studies, showing decreased cognitive performance after administration of APO and the dopamine agonist pramipexole (Hamidovic et al. 2008; Schellekens et al. 2009). Since dopamine receptors in the prefrontal cortex (PFC) are located both at the presynaptic and postsynaptic neuron, one could speculate that the disruptive effect on cognitive performance is caused by decreased dopamine functioning after stimulation of presynaptic dopamine receptors or excessive dopamine functioning after stimulation of postsynaptic dopamine receptors (al-Tikriti et al. 1992; Wang and Pickel 2002).

In contrast with the hypotheses, participants with poor baseline cognitive performance were most sensitive to the deteriorating effects of APO on cognitive performance. That individuals with presumed lower levels of prefrontal dopamine functioning are more sensitive to the detrimental effects of APO on cognitive performance suggests that stimulation of presynaptic dopamine receptors, and subsequently reduced dopamine neurotransmission in the PFC is involved. Further studies are needed to explore the
Fig. 5 Results: percentage prepulse inhibition (PPI) before and after sublingual $(2 \mathrm{mg})$ and subcutaneous $(0.005 \mathrm{mg} / \mathrm{kg})$ administration of apomorphine (APO) on $75 \mathrm{~dB}$ and $85 \mathrm{~dB}$ prepulse trials. a Percentage PPI on $75 \mathrm{~dB}$ prepulse trials by high vs. low baseline levels of PPI. b Percentage PPI on $85 \mathrm{~dB}$ prepulse trials

a) percentage PPI on $75 \mathrm{~dB}$ prepulse trials, by high vs. low baseline levels of PPI.

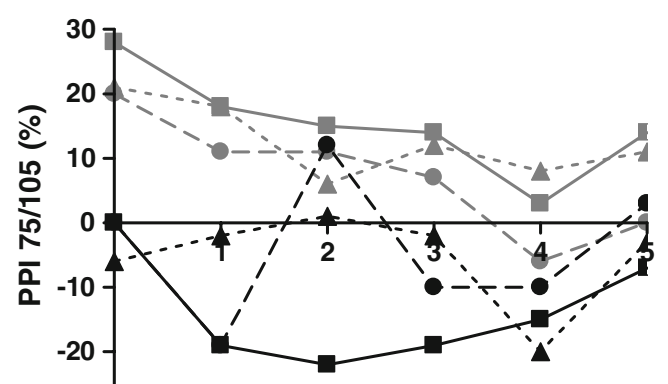

b) percentage PPI on $85 \mathrm{~dB}$ prepulse trials.

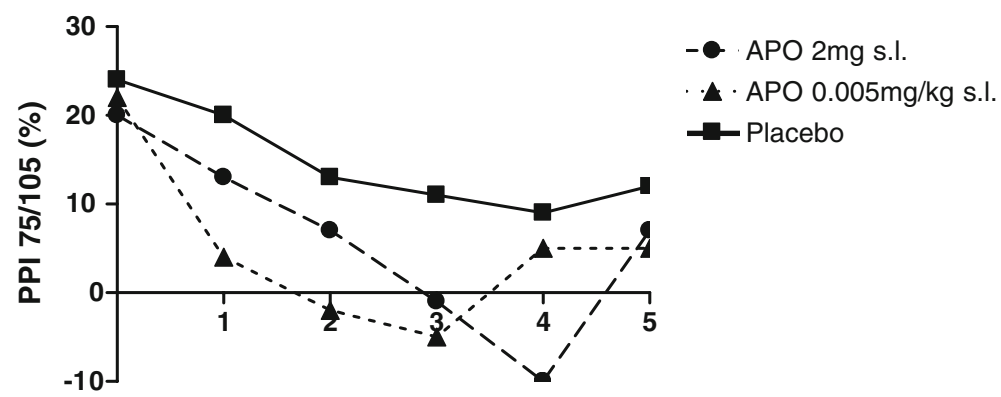

high baseline gating

- APO 2mg s.l.

^. APO $0.005 \mathrm{mg} / \mathrm{kg}$ s.c.

- Placebo

low baseline gating

- APO $2 \mathrm{mg} \mathrm{s} . \mathrm{l}$.

« APO $0.005 \mathrm{mg} / \mathrm{kg}$ s.c.

- Placebo 
Fig. 6 Results: relation between apomorphine (APO) levels in the first and second compartment (blood and brain) and time-locked plasma growth hormone $(\mathrm{GH})$ levels and error percentage on the AXcontinuous performance task (AX-CPT). a GH after $0.005 \mathrm{mg} / \mathrm{kg}$ APO s.c. b Error percentage on AX-CPT after $0.005 \mathrm{mg} / \mathrm{kg}$ APO s.l. a) $\mathrm{GH}$ after $0.005 \mathrm{mg} / \mathrm{kg}$ APO s.c.

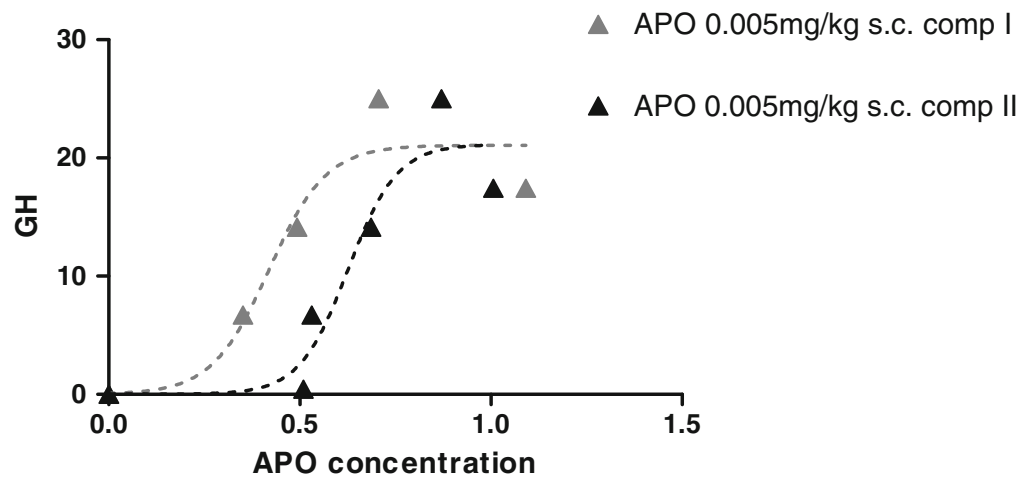

b) Error percentage on AX-CPT after $0.005 \mathrm{mg} / \mathrm{kg}$ APO s.1.

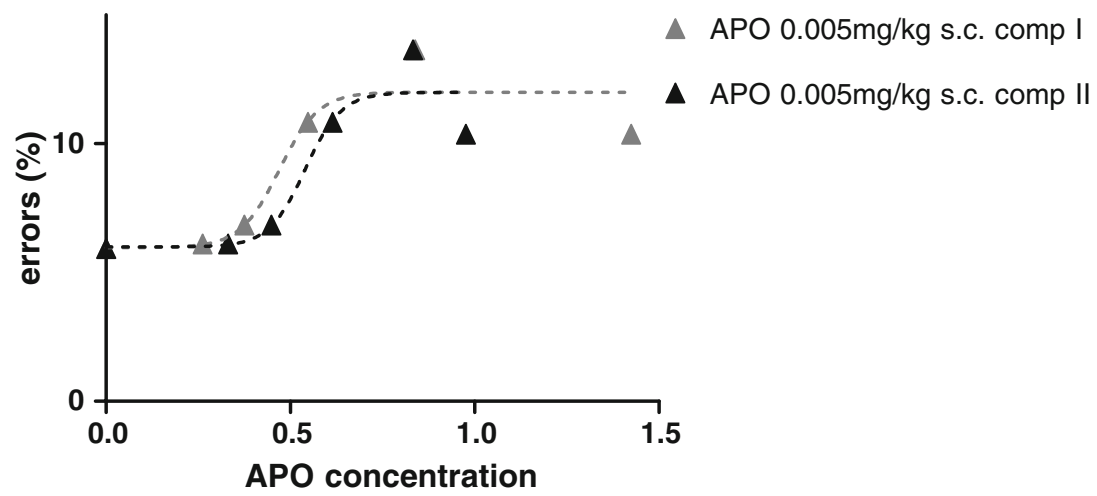

mechanisms underlying the effect of APO on cognitive performance.

The observation of PPI disruption in high-intensity prepulse trials after administration of APO, versus PPI enhancement in low intensity prepulse trials, is in line with previous findings with the dopamine agonists pergolide and 4-propyl-9-hydroxynaphthoxazine in rats (Martin-Iverson and Else 2000; Swerdlow et al. 2001a, b). This paradoxical finding has been hypothesized to result from either agonist action on dopamine receptors located pre and post synaptically, or at different parts in the startle neurocircuitry, or from agonist action on different neurochemical subclasses of dopamine receptors, e.g., D3 and D4 (MartinIverson and Else 2000; Swerdlow et al. 2001b).

Although dopamine receptors are located in several different brain areas, there is substantial evidence from preclinical research suggesting that the final pathway in the disruptive effect of APO on PPI is dependent on stimulation of dopamine receptors in the nucleus accumbens. Local application of dopamine agonists in the nucleus accumbens, but not in the neostriatum or the orbitofrontal cortex, reduces PPI (Swerdlow et al. 1992; Wan et al. 1994). Interestingly, within the prefrontal cortex, dopamine antagonists rather than agonists appear to decrease PPI

Table 2 Mean correlations between central outcome measures (plasma GH levels and performance on the AX-continuous performance task (CPT-AX)) and apomorphine (APO) levels in plasma as calculated in the second compartment

\begin{tabular}{|c|c|c|c|c|c|}
\hline \multirow{3}{*}{$\begin{array}{l}\text { APO } 0.005 \mathrm{mg} / \mathrm{kg} \text { s.c. } \\
\text { 1st compartment }\end{array}$} & \multirow{2}{*}{$\begin{array}{l}\mathrm{GH}, \text { mean R (SD) } \\
N=8\end{array}$} & \multicolumn{2}{|c|}{$\mathrm{AX}-\mathrm{CPT}$, mean $\mathrm{R}(\mathrm{SD})$ reaction time errors } & \multicolumn{2}{|c|}{ PPI, mean R (SD) 75/105dB 85/105dB } \\
\hline & & $N=9$ & $N=9$ & $N=9$ & $N=9$ \\
\hline & $0.20(0.30)$ & $0.41(0.48)$ & $0.58(0.37)$ & $.289(.25)$ & $-.175(.44)$ \\
\hline 2nd compartment & $0.58(0.20)$ & $0.45(0.44)$ & $0.58(0.37)$ & $.282(.35)$ & $-.178(.39)$ \\
\hline APO 2 mg s.l. & $N=5$ & $N=5$ & $N=5$ & $N=5$ & $N=5$ \\
\hline 1st compartment & $0.01(0.27)$ & $0.46(0.43)$ & $0.33(0.37)$ & $.074(.41)$ & $-.192(.33)$ \\
\hline 2nd compartment & $0.30(0.41)$ & $0.43(0.43)$ & $0.46(0.36)$ & $.137(.22)$ & $-.373(.32)$ \\
\hline
\end{tabular}


(Ellenbroek et al. 1996; Zavitsanou et al. 1999). More importantly, Swerdlow and colleagues also showed that the PPI disruptive effect of systemically applied dopamine agonists can be blocked by blocking dopamine transmission in the nucleus accumbens (Swerdlow et al. 1990). These data suggest that the effects of dopamine agonists on PPI are predominantly mediated via the mesolimbic, nucleus accumbens, and dopamine receptors. However, it cannot be ruled out that the disruptive effect of APO on PPI may be mediated by dopamine receptors in the medial prefrontal cortex (Broersen et al. 1999; Lacroix et al. 2000).

At low prepulse intensities, APO-improved sensorimotor gating in participants with suboptimal baseline levels of PPI with presumed suboptimal mesolimbic dopamine functioning. This suggests that stimulation of postsynaptic dopamine receptors and subsequently increased mesolimbic dopamine neurotransmission is involved. In contrast, baseline levels of PPI did not modify the response to APO in high-intensity prepulse trials. PPI on high-intensity prepulse trials is rather robust and likely less sensitive to the effect of baseline PPI on APO sensitivity. Yet, at low prepulse intensities, PPI may be dependent on a more narrow optimum of mesolimbic dopamine functioning.

The observed negative correlation between baseline cognitive performance and baseline PPI on low intensity prepulse trials supports a previously suggested reciprocal relation between prefrontal and subcortical dopamine neurotransmission (Kellendonk et al. 2006; Wilkinson 1997). Participants with high baseline cognitive performance, i.e., presumed optimal prefrontal dopamine functioning showed impaired levels of sensorimotor gating, i.e., presumed suboptimal mesolimbic dopamine functioning. Moreover, subjects sensitive to deteriorating effects of APO on cognitive performance appeared to be less sensitive to the PPI enhancing effects of APO. This again supports the idea that whereas cognitive performance is more related to cortical dopaminergic systems, PPI is more mediated via mesolimbic dopaminergic systems.

Yet, it has previously been suggested that sensorimotor gating is a pre-attentional function, important for the integrity of higher order cognitive processes (Braff and Geyer 1990). Previous studies have indeed shown levels of PPI to correlate with attention and planning ability (Bitsios and Giakoumaki 2005; Csomor et al. 2008; Giakoumaki et al. 2006). These findings merit further investigation with respect to the relation between sensorimotor gating and higher order cognitive processes.

Several additional issues regarding PPI need to be considered. First, the number of excluded startle trials in this study (20\%) is high compared to literature $(5 \%)$ (Bitsios et al. 2005; Braff et al. 1992; Liechti et al. 2001; van der Linden et al. 2006). Moreover, the number of excluded trials increased over consecutive startle sessions.
This may result from both habituation and weariness of the participants due to repeated measurement sessions. Though there was no effect of treatment on the number of excluded trials, habituation effects may have influenced the observed effects of APO on PPI. Importantly, we used a low dose of APO $(0.005 \mathrm{mg} / \mathrm{kg}$ s.c. or $2 \mathrm{mg}$ s.l. $)$ compared to animal literature (e.g., $0.5 \mathrm{mg} / \mathrm{kg}$ ). Direct translation of the current findings to animal findings is, therefore, limited.

The effect of APO on the central outcome measures closely follows the kinetics of APO. In line with our hypotheses, we found the best correlation between central outcome measures and calculated APO levels in the second compartment (CSF) after s.c. administration. APO levels in the second compartment show an S-curve relation with central outcome measures, whereas plasma APO concentrations (first compartment) show a poor correlation due to a large counter-clock hysteresis curve. The use of twocompartmental pharmacokinetic/pharmacodynamic (PK/PD) modeling may provide further insight in true pharmacodynamic differences in dopamine receptor sensitivity between groups taking into account pharmacokinetic differences. Since correlation coefficients were rather low, factors other than APO levels may contribute to the observed changes in central outcome measures like weariness, motivational decline, habituation to the acoustic startle, and a learning effect on the AX-CPT. In addition, PK/PD analyses were based on a limited number of participants. Future studies are needed to confirm the current findings.

\section{Conclusions}

The apomorphine challenge test appears a useful tool to assess dopamine receptor functioning at the level of the forebrain. Baseline performance modulated the effect of APO on task performance and PPI. This may be explained by the hypothesized inverted U-shape relation between prefrontal dopamine functioning and cognitive performance and mesolimbic dopamine functioning and sensorimotor gating. The current findings also suggest a reciprocal relation between prefrontal and mesolimbic dopamine functioning.

More studies on the relation between the central effects of APO and levels of APO in the CSF are needed. Future APO challenge studies into dopamine dysfunctioning in neuropsychiatric disorders preferably use multiple outcome measures after s.c. administration.

Acknowledgments The research was supported by a governmental grant from ZonMW (31000059).

We like to acknowledge all participants of the study for their efforts.

Statement of interest None to be reported. 
Open Access This article is distributed under the terms of the Creative Commons Attribution Noncommercial License which permits any noncommercial use, distribution, and reproduction in any medium, provided the original author(s) and source are credited.

\section{References}

al-Tikriti MS, Roth RH, Kessler RM, Innis RB (1992) Autoradiographic localization of dopamine D1 and D2 receptors in rat cerebral cortex following unilateral neurotoxic lesions. Brain Res 575:39-46

Aymard G, Berlin I, de Brettes B, Diquet B (2003) Pharmacokineticpharmacodynamic study of apomorphine's effect on growth hormone secretion in healthy subjects. Fundam Clin Pharmacol $17: 473-481$

Backman L, Ginovart N, Dixon RA, Wahlin TB, Wahlin A, Halldin C, Farde L (2000) Age-related cognitive deficits mediated by changes in the striatal dopamine system. Am J Psychiatry 157:635-637

Bitsios P, Giakoumaki SG (2005) Relationship of prepulse inhibition of the startle reflex to attentional and executive mechanisms in man. Int J Psychophysiol 55:229-241

Bitsios P, Giakoumaki SG, Frangou S (2005) The effects of dopamine agonists on prepulse inhibition in healthy men depend on baseline PPI values. Psychopharmacology (Berl) 182:144-152

Braff DL, Geyer MA (1990) Sensorimotor gating and schizophrenia. Human and animal model studies. Arch Gen Psychiatry 47:181-188

Braff DL, Grillon C, Geyer MA (1992) Gating and habituation of the startle reflex in schizophrenic patients. Arch Gen Psychiatry 49:206-215

Braff DL, Geyer MA, Swerdlow NR (2001) Human studies of prepulse inhibition of startle: normal subjects, patient groups, and pharmacological studies. Psychopharmacology (Berl) 156(2-3):234 58 , July

Braver TS, Barch DM, Keys BA, Carter CS, Cohen JD, Kaye JA, Janowsky JS, Taylor SF, Yesavage JA, Mumenthaler MS, Jagust WJ, Reed BR (2001) Context processing in older adults: evidence for a theory relating cognitive control to neurobiology in healthy aging. J Exp Psychol Gen 130:746-763

Broersen LM, Feldon J, Weiner I (1999) Dissociative effects of apomorphine infusions into the medial prefrontal cortex of rats on latent inhibition, prepulse inhibition and amphetamineinduced locomotion. Neuroscience 94:39-46

Cools R (2008) Role of dopamine in the motivational and cognitive control of behavior. Neuroscientist 14:381-395

Cropley VL, Fujita M, Innis RB, Nathan PJ (2006) Molecular imaging of the dopaminergic system and its association with human cognitive function. Biol Psychiatry 59:898-907

Csomor PA, Stadler RR, Feldon J, Yee BK, Geyer MA, Vollenweider FX (2008) Haloperidol differentially modulates prepulse inhibition and p50 suppression in healthy humans stratified for low and high gating levels. Neuropsychopharmacology 33:497-512

Duval F, Mokrani MC, Crocq MA, Bailey PE, Diep TS, Correa H, Macher JP (2000) Dopaminergic function and the cortisol response to dexamethasone in psychotic depression. Prog Neuropsychopharmacol Biol Psychiatry 24:207-225

Ellenbroek BA, Budde S, Cools AR (1996) Prepulse inhibition and latent inhibition: the role of dopamine in the medial prefrontal cortex. Neuroscience 75:535-542

Essink AW, Lohuis CP, Klein Elhorst JT, Rutten WJ (1991) Selective and quantitative isolation and determination of apomorphine in human plasma. J Chromatogr 570:419-424
Fleming K, Bigelow LB, Weinberger DR, Goldberg TE (1995) Neuropsychological effects of amphetamine may correlate with personality characteristics. Psychopharmacol Bull 31:357-362

Fletcher PC, Frith CD, Grasby PM, Friston KJ, Dolan RJ (1996) Local and distributed effects of apomorphine on fronto-temporal function in acute unmedicated schizophrenia. J Neurosci 16:7055-7062

Frank MJ, O'Reilly RC (2006) A mechanistic account of striatal dopamine function in human cognition: psychopharmacological studies with cabergoline and haloperidol. Behav Neurosci 120:497-517

Friston KJ, Grasby PM, Bench CJ, Frith CD, Cowen PJ, Liddle PF, Frackowiak RS, Dolan R (1992) Measuring the neuromodulatory effects of drugs in man with positron emission tomography. Neurosci Lett 141:106-110

Giakoumaki SG, Bitsios P, Frangou S (2006) The level of prepulse inhibition in healthy individuals may index cortical modulation of early information processing. Brain Res 1078:168-170

Gibbs SE, D'Esposito M (2005) A functional MRI study of the effects of bromocriptine, a dopamine receptor agonist, on component processes of working memory. Psychopharmacology (Berl) 180:644-653

Grasby PM, Friston KJ, Bench CJ, Cowen PJ, Frith CD, Liddle PF, Frackowiak RS, Dolan RJ (1993) The effect of the dopamine agonist, apomorphine on regional cerebral blood flow in normal volunteers. Psychol Med 23:605-612

Hamidovic A, Kang UJ, de Wit H (2008) Effects of low to moderate acute doses of pramipexole on impulsivity and cognition in healthy volunteers. J Clin Psychopharmacol 28:45-51

Hofstee DJ, Neef C, van Laar T, Jansen EN (1994) Pharmacokinetics of apomorphine in Parkinson's disease: plasma and cerebrospinal fluid levels in relation to motor responses. Clin Neuropharmacol $17: 45-52$

Iversen SD, Iversen LL (2007) Dopamine: 50 years in perspective. Trends Neurosci 30:188-193

Kellendonk C, Simpson EH, Polan HJ, Malleret G, Vronskaya S, Winiger V, Moore H, Kandel ER (2006) Transient and selective overexpression of dopamine D2 receptors in the striatum causes persistent abnormalities in prefrontal cortex functioning. Neuron 49:603-615

Kienast T, Heinz A (2006) Dopamine and the diseased brain. CNS Neurol Disord Drug Targets 5:109-131

Kimberg DY, D'Esposito M, Farah MJ (1997) Effects of bromocriptine on human subjects depend on working memory capacity. Neuroreport 8:3581-3585

Lacroix L, Broersen LM, Feldon J, Weiner I (2000) Effects of local infusions of dopaminergic drugs into the medial prefrontal cortex of rats on latent inhibition, prepulse inhibition and amphetamine induced activity. Behav Brain Res 107:111-121

Langeland W, van den Brink W, Draijer N, Hartgers C (2001) Sensitivity of the Addiction Severity Index physical and sexual assault items: preliminary findings on gender differences. Eur Addict Res 7:193-197

Liechti ME, Geyer MA, Hell D, Vollenweider FX (2001) Effects of MDMA (ecstasy) on prepulse inhibition and habituation of startle in humans after pretreatment with citalopram, haloperidol, or ketanserin. Neuropsychopharmacology 24:240-252

Martin-Iverson MT, Else D (2000) PHNO, a selective dopamine D2 receptor agonist, does not reduce prepulse inhibition of the startle reflex in rats. Psychopharmacology (Berl) 151:38-48

Mattay VS, Callicott JH, Bertolino A, Heaton I, Frank JA, Coppola R, Berman KF, Goldberg TE, Weinberger DR (2000) Effects of dextroamphetamine on cognitive performance and cortical activation. Neuroimage 12:268-275

Mattay VS, Goldberg TE, Fera F, Hariri AR, Tessitore A, Egan MF, Kolachana B, Callicott JH, Weinberger DR (2003) Catechol O- 
methyltransferase val158-met genotype and individual variation in the brain response to amphetamine. Proc Natl Acad Sci USA 100:6186-6191

McLellan AT, Kushner H, Metzger D, Peters R, Smith I, Grissom G, Pettinati H, Argeriou M (1992) The fifth edition of the Addiction Severity Index. J Subst Abuse Treat 9:199-213

Mehta MA, Swainson R, Ogilvie AD, Sahakian J, Robbins TW (2001) Improved short-term spatial memory but impaired reversal learning following the dopamine $\mathrm{D}(2)$ agonist bromocriptine in human volunteers. Psychopharmacology (Berl) 159:10-20

Meister B, Hokfelt T, Vale WW, Goldstein M (1985) Growth hormone releasing factor (GRF) and dopamine coexist in hypothalamic arcuate neurons. Acta Physiol Scand 124:133-136

Mokrani MC, Duval F, Crocq MA, Bailey PE, Macher JP (1995) Multihormonal responses to apomorphine in mental illness. Psychoneuroendocrinology 20:365-375

Neef C, Jelliffe RW, van Laar T, Loohuis T, Essink AW, Janssen EN (1994) Comparison of two software programs to be used for the calculation of population pharmacokinetic parameters. Int $\mathrm{J}$ Biomed Comput 36:143-150

Neef C, van Laar T (1999) Pharmacokinetic-pharmacodynamic relationships of apomorphine in patients with Parkinson's disease. Clin Pharmacokinet 37:257-271

Reeves SJ, Grasby PM, Howard RJ, Bantick RA, Asselin MC, Mehta MA (2005) A positron emission tomography (PET) investigation of the role of striatal dopamine (D2) receptor availability in spatial cognition. Neuroimage 28:216-226

Sandra Kooij JJ, Marije BA, Swinkels SH, Bekker EM, de Noord I, Buitelaar JK (2008) Reliability, validity, and utility of instruments for self-report and informant report concerning symptoms of ADHD in adult patients. J Atten Disord 11:445-458

Schellekens AF, van Oosterwijck AW, Ellenbroek B, de Jong CA, Buitelaar JK, Cools L, Verkes RJ (2009) The dopamine agonist apomorphine differentially affects cognitive performance in alcohol dependent patients and healthy controls. Eur Neuropsychopharmacol 19:68-73

Schmidt K, Nolte-Zenker B, Patzer J, Bauer M, Schmidt LG, Heinz A (2001) Psychopathological correlates of reduced dopamine receptor sensitivity in depression, schizophrenia, and opiate and alcohol dependence. Pharmacopsychiatry 34:66-72

Seeman P, Van Tol HH (1993) Dopamine receptor pharmacology. Curr Opin Neurol Neurosurg 6:602-608

Sheehan DV, Lecrubier Y, Sheehan KH, Amorim P, Janavs J, Weiller E, Hergueta T, Baker R, Dunbar GC (1998) The Mini-International Neuropsychiatric Interview (M.I.N.I.): the development and validation of a structured diagnostic psychiatric interview for DSM-IV and ICD-10. J Clin Psychiatry 59(Suppl 20):22-33

Swainson R, Rogers RD, Sahakian BJ, Summers BA, Polkey CE, Robbins TW (2000) Probabilistic learning and reversal deficits in patients with Parkinson's disease or frontal or temporal lobe lesions: possible adverse effects of dopaminergic medication. Neuropsychologia 38:596-612

Swerdlow NR, Braff DL, Geyer MA (2000) Animal models of deficient sensorimotor gating: what we know, what we think we know, and what we hope to know soon. Behav Pharmacol 11:185-204

Swerdlow NR, Caine SB, Geyer MA (1992) Regionally selective effects of intracerebral dopamine infusion on sensorimotor gating of the startle reflex in rats. Psychopharmacology (Berl) 108:189195

Swerdlow NR, Geyer MA, Braff DL (2001a) Neural circuit regulation of prepulse inhibition of startle in the rat: current knowledge and future challenges. Psychopharmacology (Berl) 156:194-215

Swerdlow NR, Mansbach RS, Geyer MA, Pulvirenti L, Koob GF, Braff DL (1990) Amphetamine disruption of prepulse inhibition of acoustic startle is reversed by depletion of mesolimbic dopamine. Psychopharmacology (Berl) 100:413-416

Swerdlow NR, Platten A, Shoemaker J, Pitcher L, Auerbach P (2001b) Effects of pergolide on sensorimotor gating of the startle reflex in rats. Psychopharmacology (Berl) 158:230-240

Talledo JA, Sutherland Owens AN, Schortinghuis T, Swerdlow NR (2009) Amphetamine effects on startle gating in normal women and female rats. Psychopharmacology (Berl) 204:165-175

van der Linden D, Massar SA, Schellekens AF, Ellenbroek BA, Verkes RJ (2006) Disrupted sensorimotor gating due to mental fatigue: preliminary evidence. Int J Psychophysiol 62(1):168-174

van Vliet I, de Beurs E (2007) The MINI-International Neuropsychiatric Interview. A brief structured diagnostic psychiatric interview for DSM-IV en ICD-10 psychiatric disorders. Tijdschr Psychiatr 49:393-397

Vijayraghavan S, Wang M, Birnbaum SG, Williams GV, Arnsten AF (2007) Inverted-U dopamine D1 receptor actions on prefrontal neurons engaged in working memory. Nat Neurosci 10:376-384

Wan FJ, Geyer MA, Swerdlow NR (1994) Accumbens D2 modulation of sensorimotor gating in rats: assessing anatomical localization. Pharmacol Biochem Behav 49:155-163

Wang H, Pickel VM (2002) Dopamine D2 receptors are present in prefrontal cortical afferents and their targets in patches of the rat caudate-putamen nucleus. J Comp Neurol 442:392-404

Wilkinson LS (1997) The nature of interactions involving prefrontal and striatal dopamine systems. J Psychopharmacol 11:143-150

Zahrt J, Taylor JR, Mathew RG, Arnsten AF (1997) Supranormal stimulation of D1 dopamine receptors in the rodent prefrontal cortex impairs spatial working memory performance. J Neurosci 17:8528-8535

Zavitsanou K, Cranney J, Richardson R (1999) Dopamine antagonists in the orbital prefrontal cortex reduce prepulse inhibition of the acoustic startle reflex in the rat. Pharmacol Biochem Behav 63:55-61 